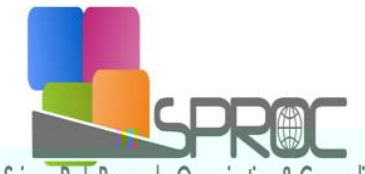

SciencePark Research, Organization \& Counseling

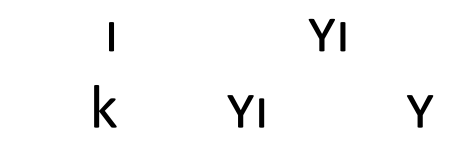

http://sproc.org/ojs/index.php/wjer

\title{
Assessment of the historical evolution of the environment in North Cyprus with regard to democratisation
}

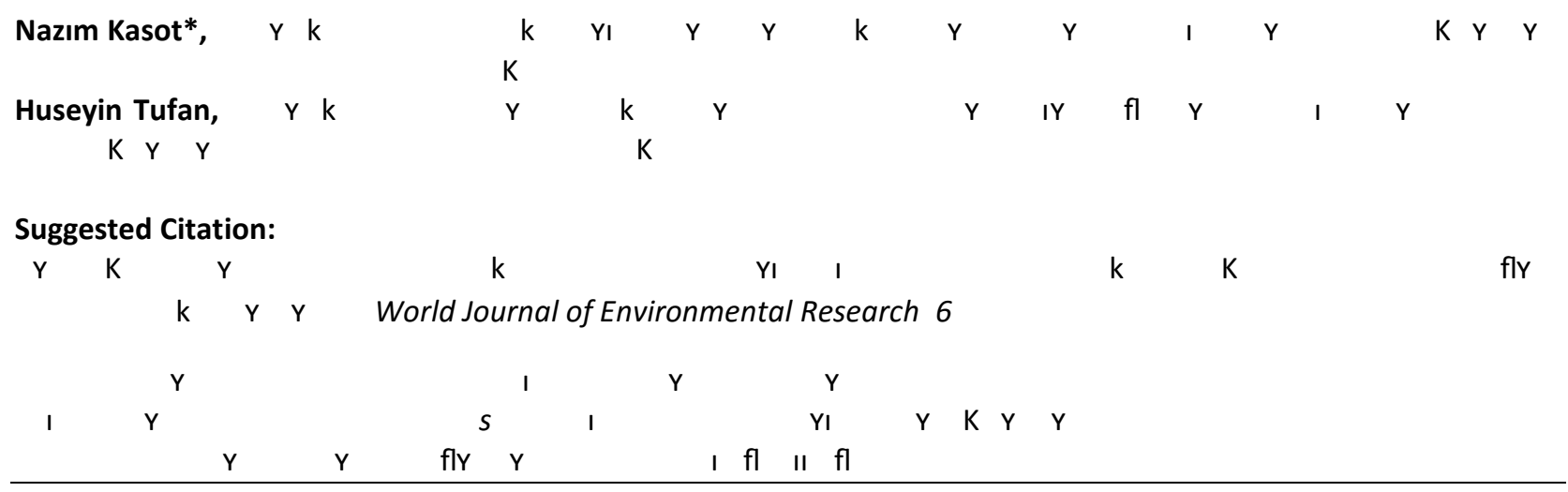

Abstract

\begin{tabular}{|c|c|c|c|c|c|c|c|c|c|c|c|c|c|c|c|c|c|c|c|c|c|}
\hline & $\mathrm{Yk}$ & & $Y$ & & IY & $\mathrm{k}$ & & k & $Y$ & $Y$ & & & $\mathrm{k}$ & & rk & $\mathrm{k}$ & & IY & & I Yk & $Y Y$ \\
\hline \multirow[t]{2}{*}{$Y$} & & k & $Y$ & $Y$ & & & $\mathrm{k}$ & $Y$ & & & & $Y$ & $\| Y$ & $Y$ & & & 1 & & fly & $Y$ & $\mathrm{Y}$ \\
\hline & & $Y$ & $Y$ & k I & 1 & & & & & $k$ & $Y$ & $Y$ & & & $k$ & & $Y$ & & & $\mathrm{YI}$ & $\mathrm{Yk}$ \\
\hline$Y$ & & & $Y \mathrm{fl}$ & & $\mathrm{YI}$ & $\mathrm{K}$ & & & & & $Y$ & & $\mathrm{k} Y$ & $Y$ & & & & & $k$ & & $Y$ \\
\hline & $\mathrm{k}$ & & & $\mathrm{k}$ & $Y Y_{I}$ & $k$ & & $Y$ & & $Y$ & $Y Y$ & II & & k & & $Y$ & 1 & & & IY & \\
\hline & $Y$ & $Y$ fl & & & $\mathrm{k}$ & $Y$ & & $Y$ & & $Y$ & & & $\mathrm{k}$ & & & $\mathrm{k}$ & $\mathrm{YI}$ & 1 & & fly & $Y$ \\
\hline
\end{tabular}

K $\quad k \quad$ k $\quad$ l $\quad k \quad r$

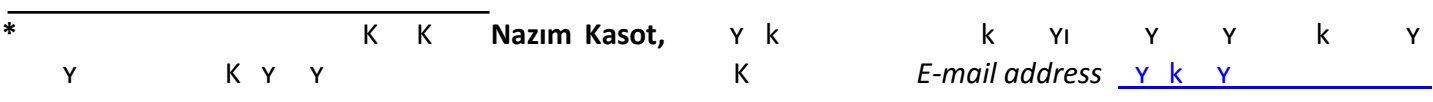

*This study is an extended version of a paper presented at 2th International History Congress of LAU which was held on 27-30 April 2015. 


\section{Introduction}

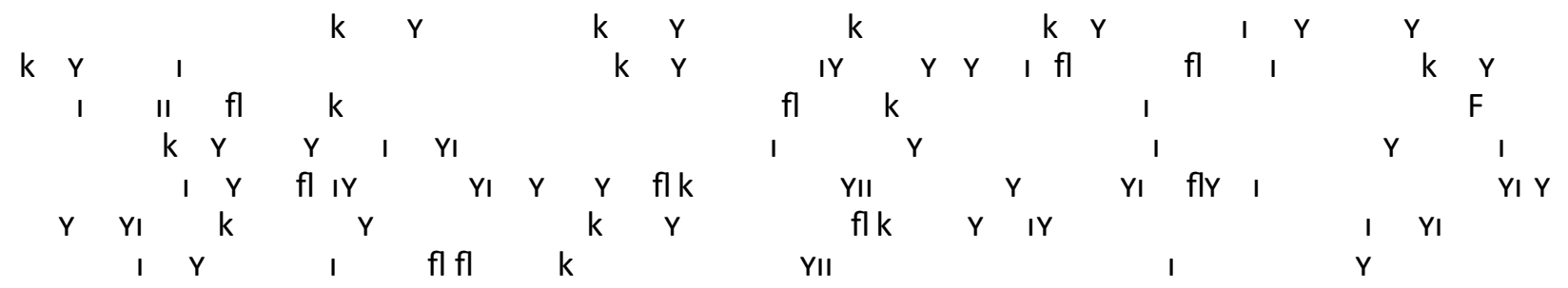

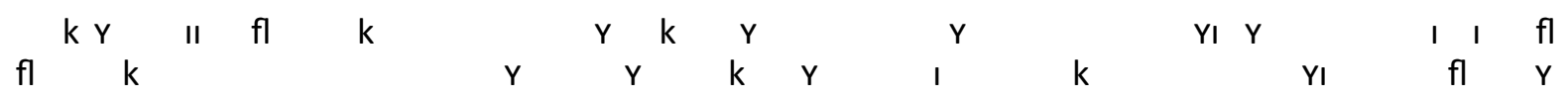

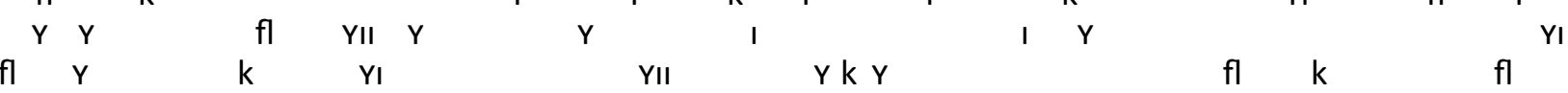

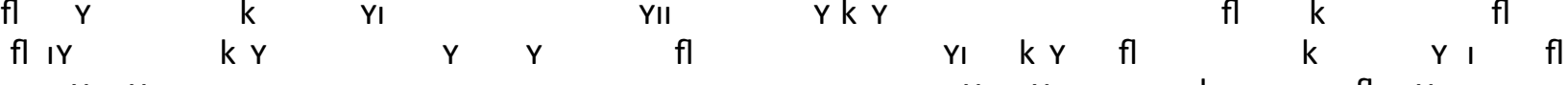

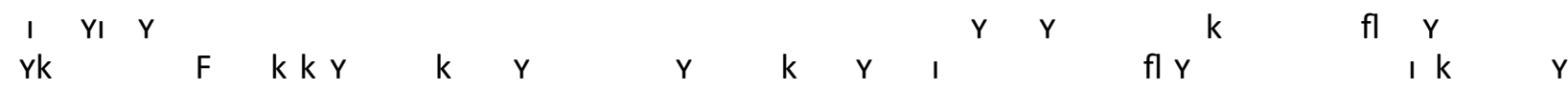

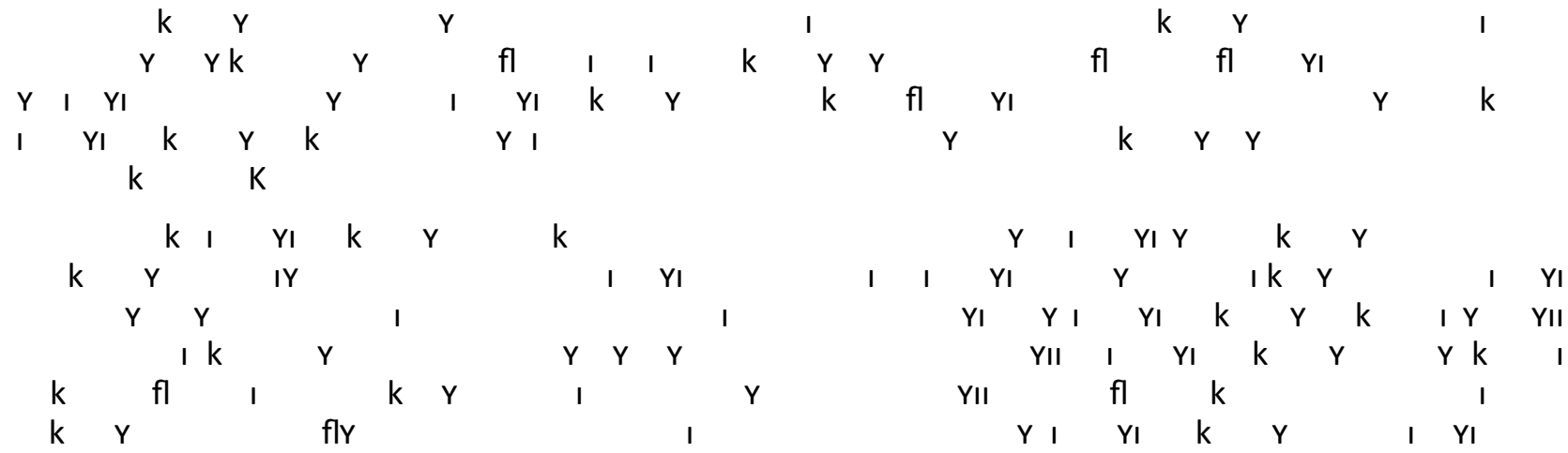

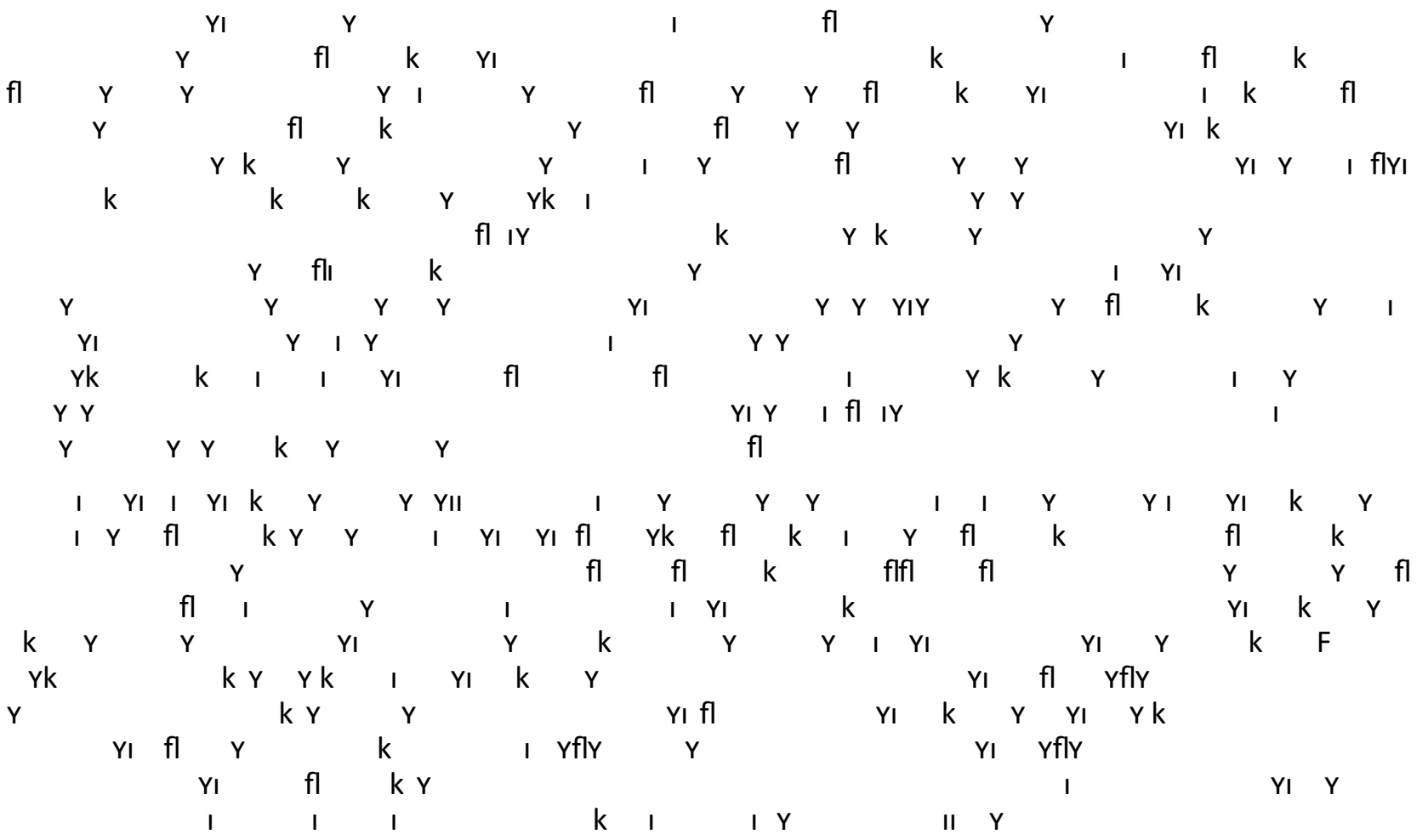




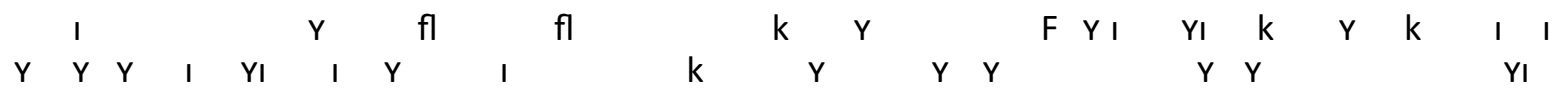

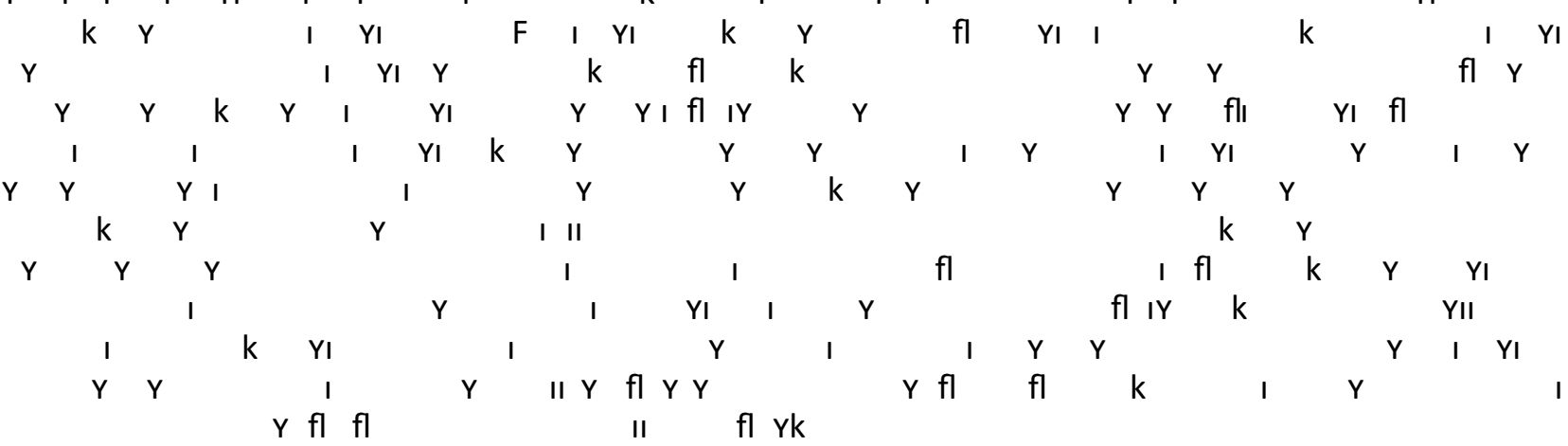
$\begin{array}{lllllllllllllll}F & k & & & Y & I & Y I & k & Y & l & Y & Y & Y\end{array}$

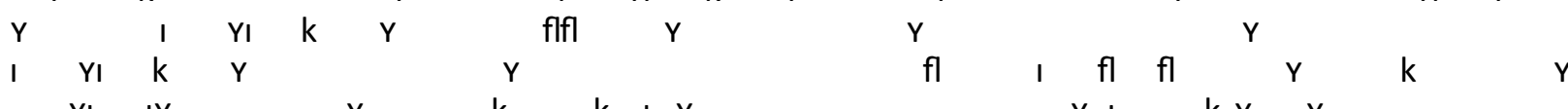

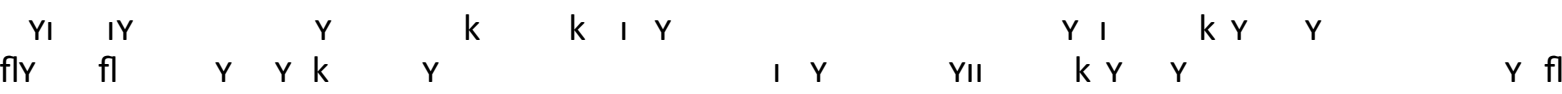

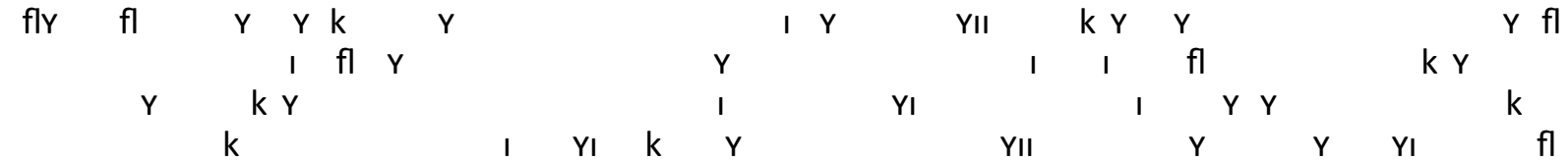

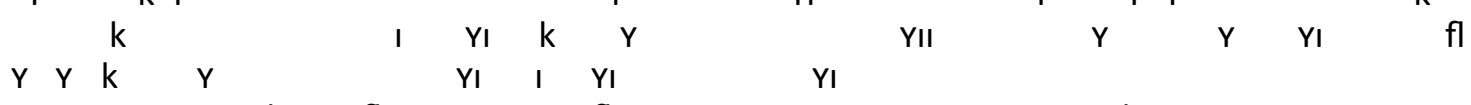

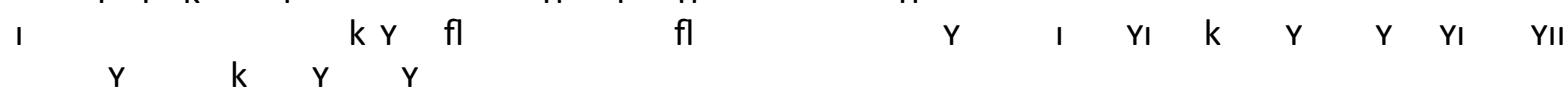

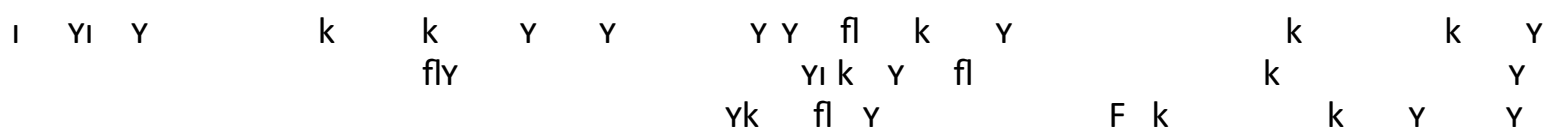
\begin{tabular}{llll}
\hline & $Y I$ & $Y$ & $Y_{1}$
\end{tabular}

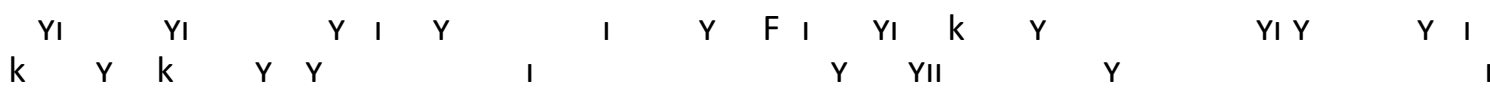
$\begin{array}{llllllllllll} & Y & Y & k & Y & Y & f l & f l\end{array}$

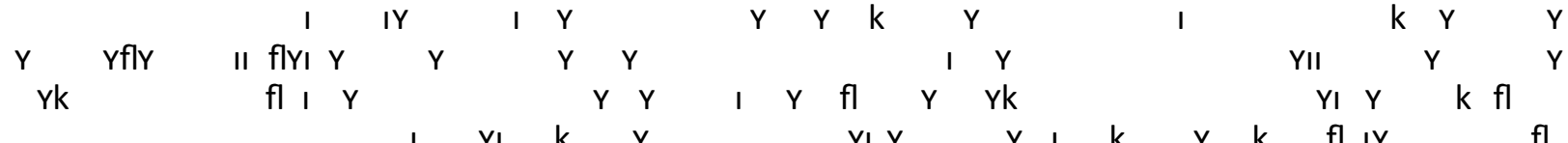

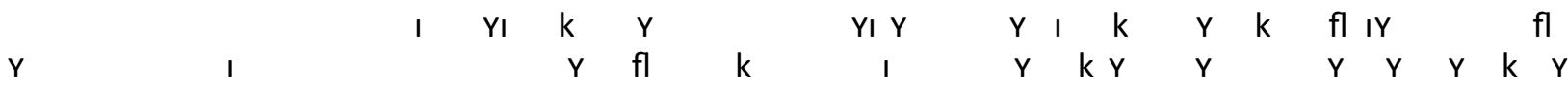

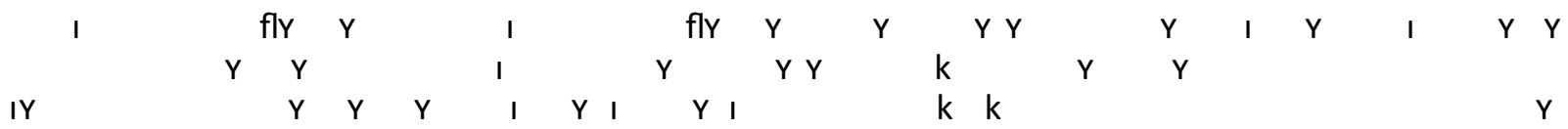

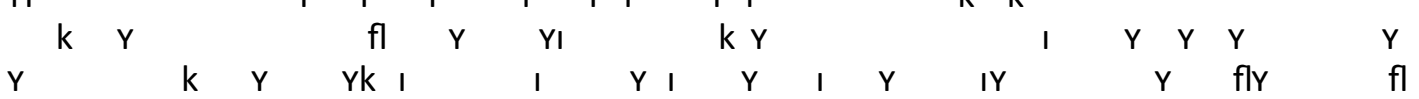
$\begin{array}{llllllllllll} & Y & Y & Y k & I & Y & Y & Y & Y & Y & Y & \text { I }\end{array}$ $\begin{array}{llllllllllll}k & Y & Y & Y & Y I I & Y & Y I f l & Y & Y & Y k\end{array}$

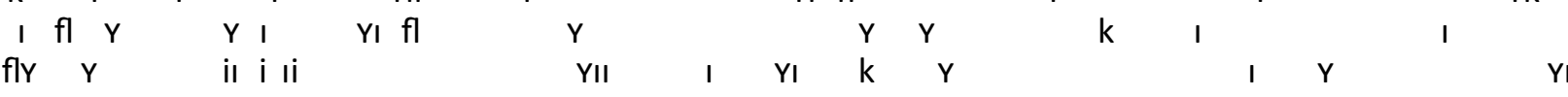

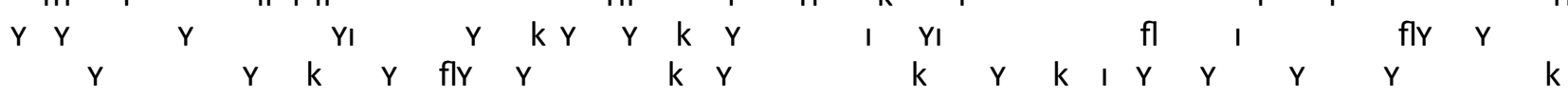
fl $Y$

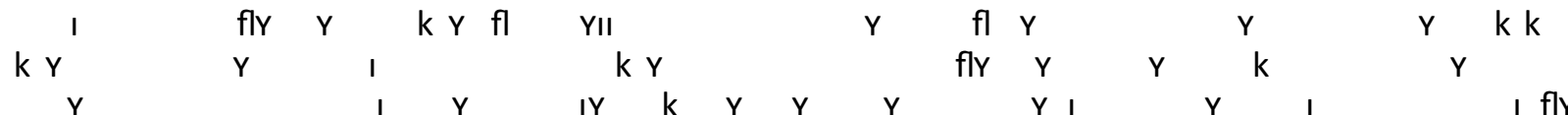

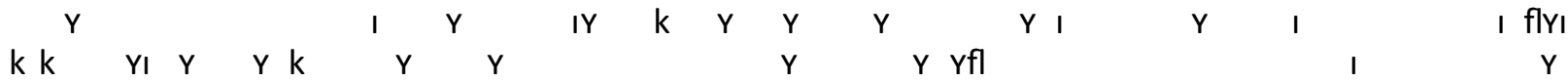

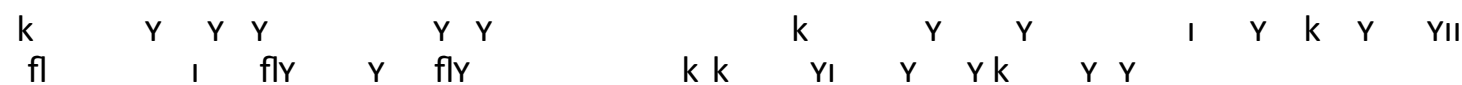




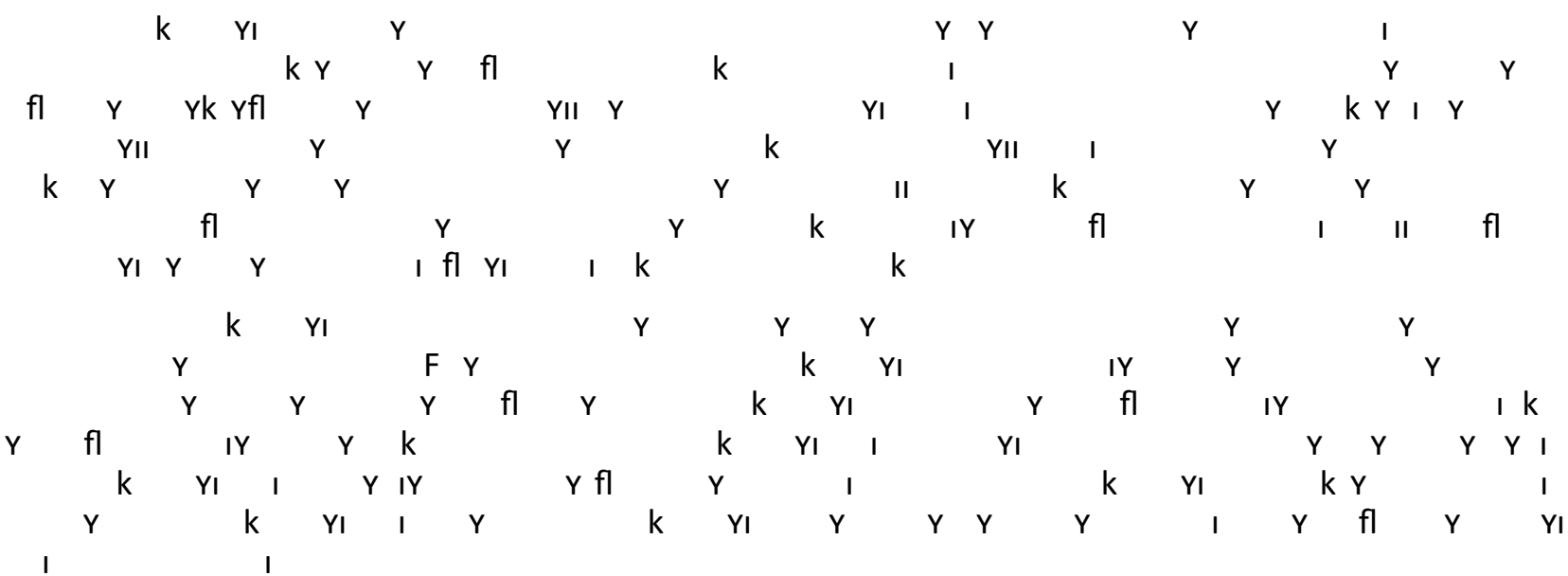

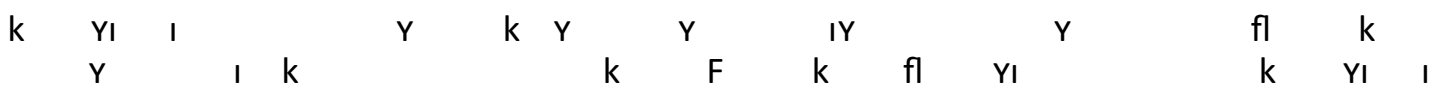

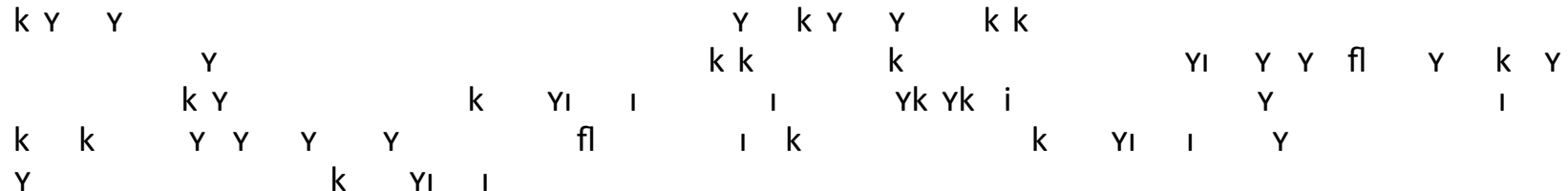

1) The impacts of environmental policies on ecological systems and distribution of population should be foreseen.

2) Some of the negative impacts may be completely eliminated, however, it may not be possible to avoid some impacts. Such impacts should be distinguished and short and long terms costs for such should be calculated.

3) The short and long term efficiencies of each investment project should be identified and the impact of long term accumulated impacts on the next generations should be estimated.

4) The potential of proposed investment projects for creating irremediable outcomes should be considered.

5) The impact of investment projects on the interests of different social groups should be avoided.

\section{Method}

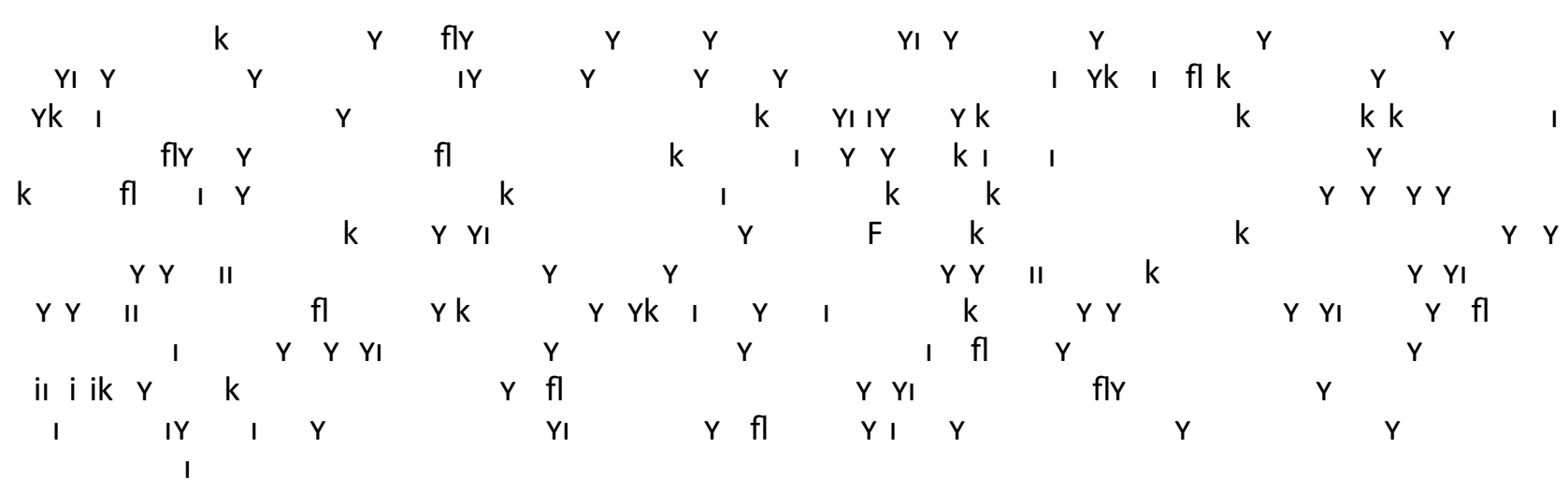

\section{Findings}

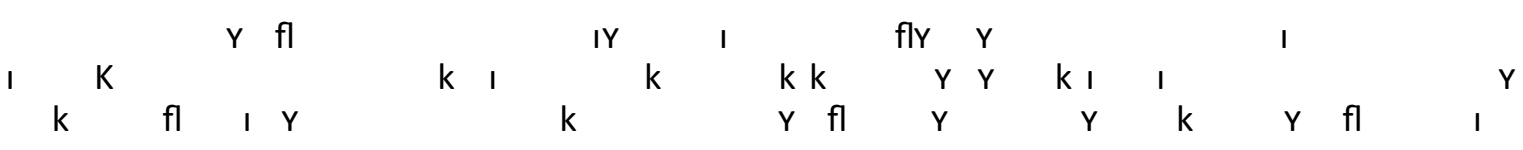




\subsection{Constitution}

$$
\begin{aligned}
& \begin{array}{lll}
\mathrm{l} & \mathrm{Y} \quad \mathrm{II}
\end{array} \\
& \begin{array}{lllllllll}
Y & f l & I & Y & Y I & Y & Y I Y & & k
\end{array}
\end{aligned}
$$

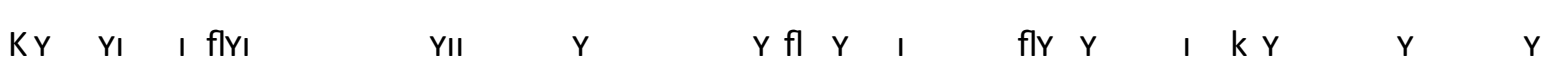

$$
\begin{aligned}
& \begin{array}{llllll}
k Y & Y I & Y f l & k Y & I & Y
\end{array}
\end{aligned}
$$

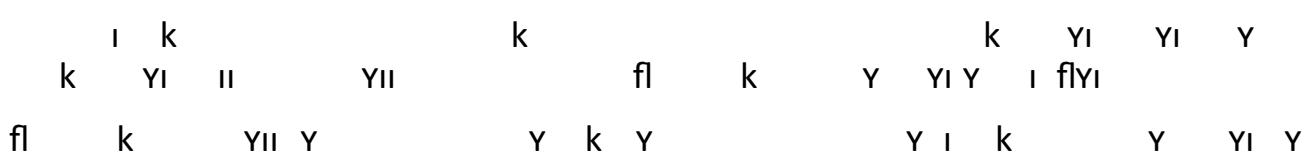

\subsection{Former and New Environment Law}
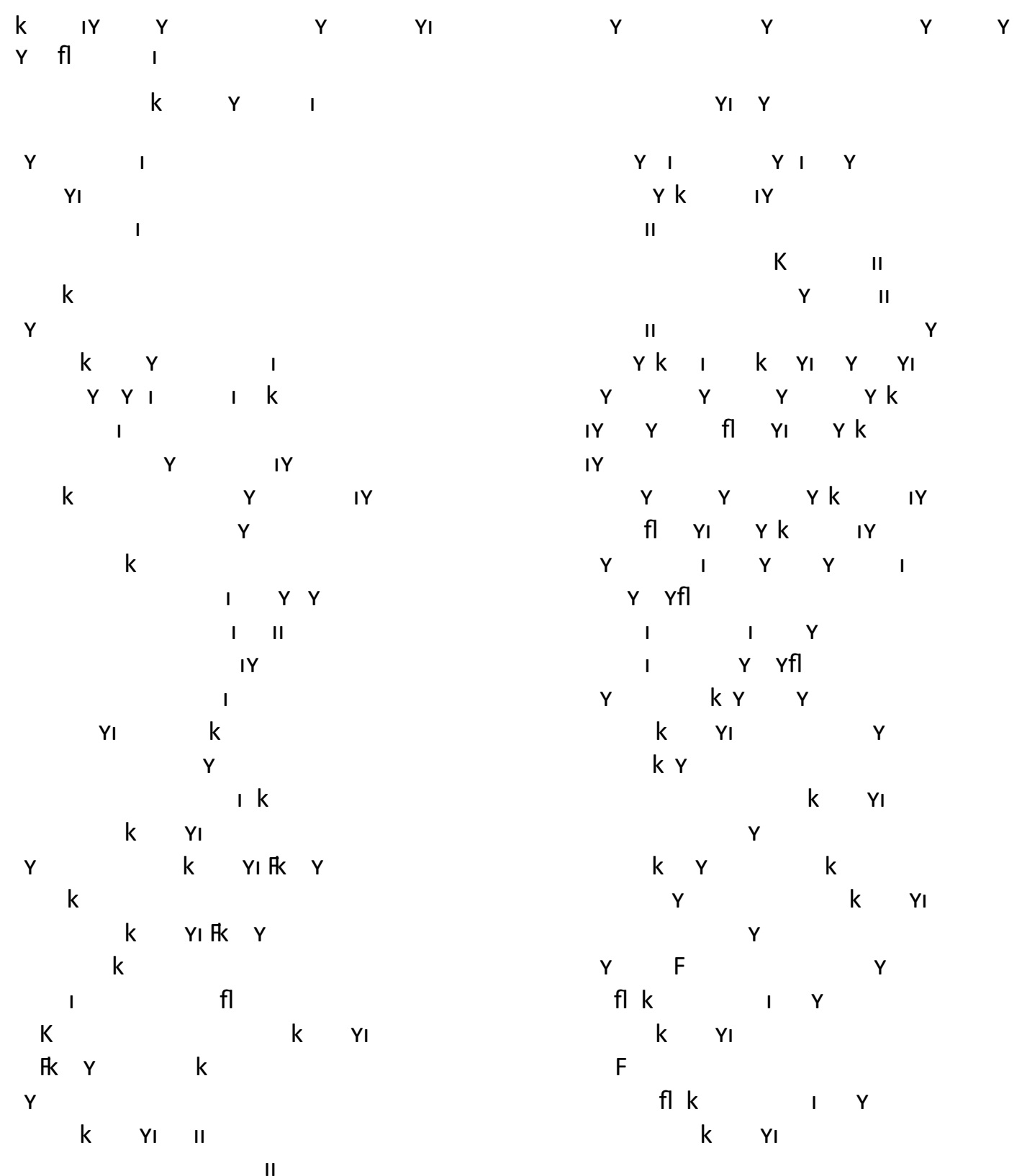
$\begin{array}{cccccc}\mathrm{Y} & \mathrm{K} & & \mathrm{Y} & \mathrm{k} & \mathrm{YI} \\ \mathrm{k} & \mathrm{Y} & \mathrm{Y} & \text { World Journal of Environmental Research } & 6\end{array}$

k K fly
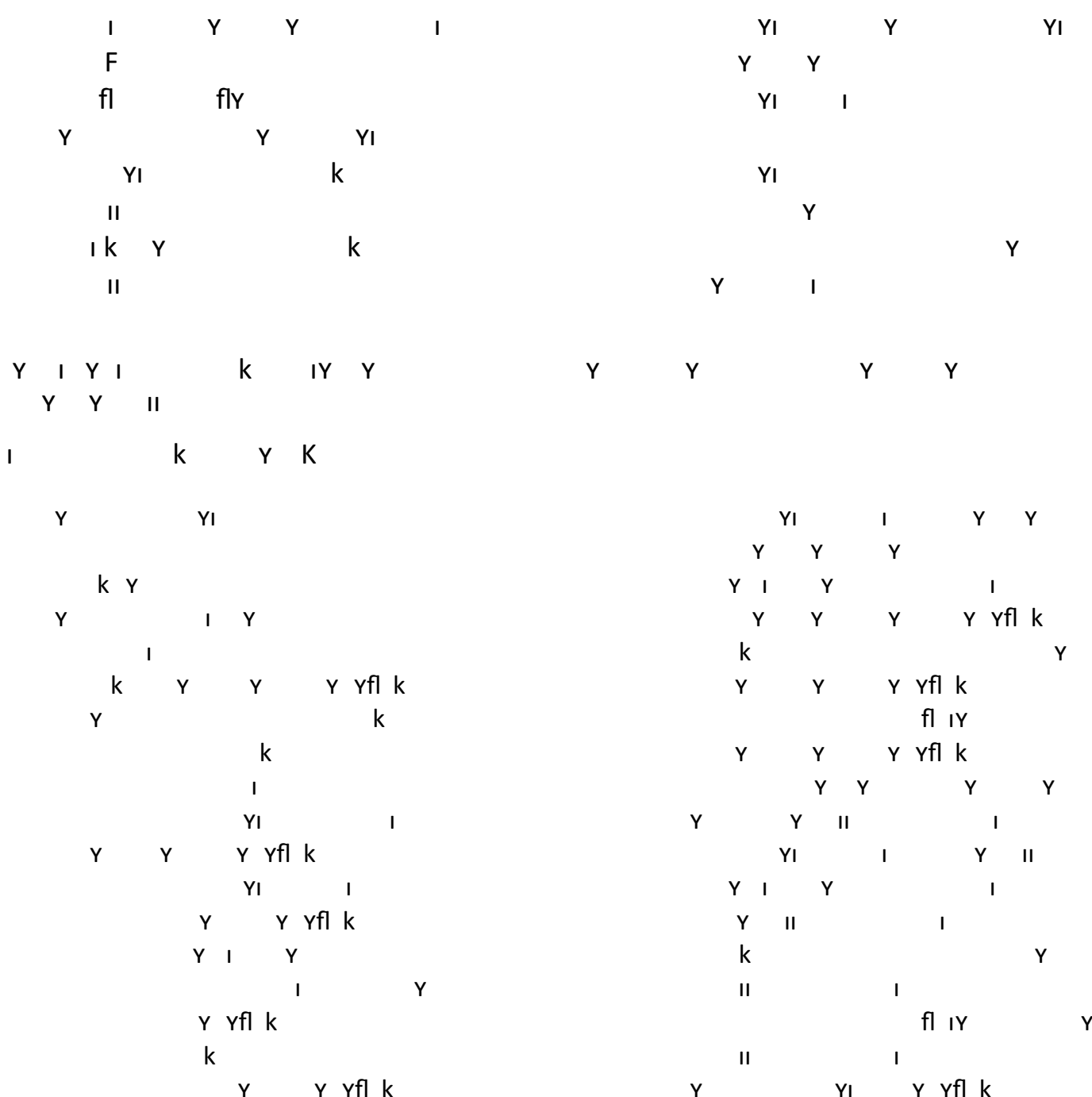

Y $\quad$ Y Yfl k

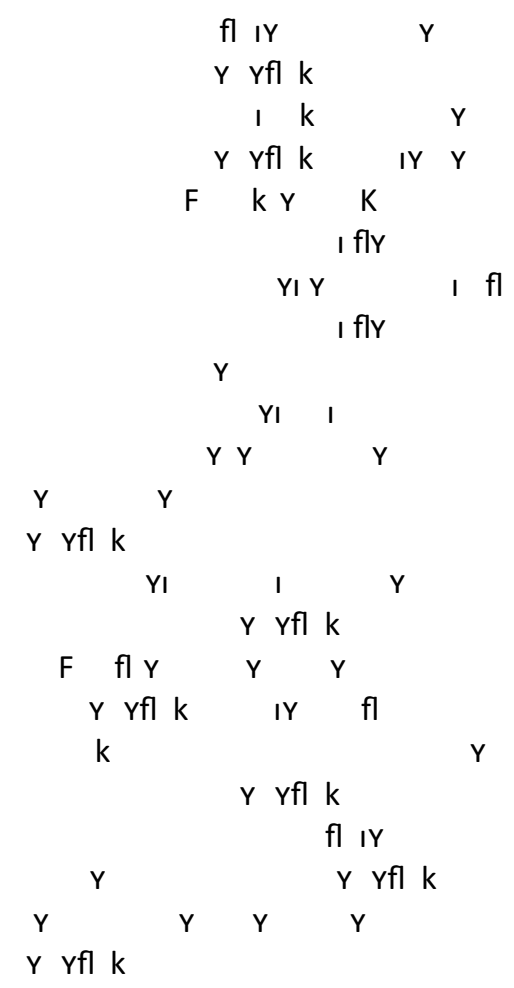

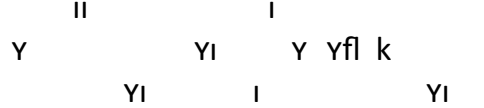

Y Yfl k

$\begin{array}{llll}Y & \mathrm{I} & \mathrm{I}\end{array}$
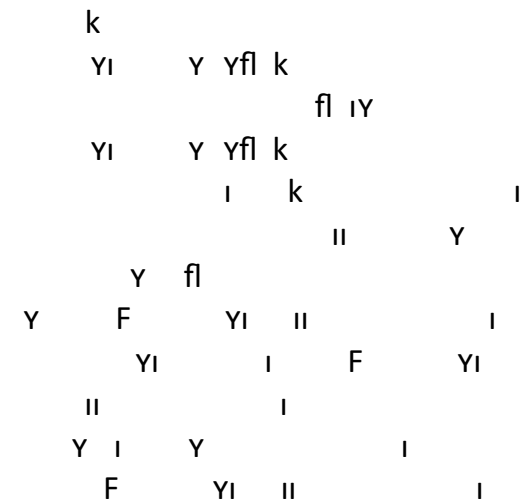

$\mathrm{F}^{\mathrm{k}}$ YI II

$\begin{array}{cccccc}F & \text { YI } & \text { II } & & \text { I } \\ \text { F } & & & \text { fl IY } & & \\ & \text { YI } & \text { II } & & \text { I } & \\ & k & & & \text { I } & \text { Y I I }\end{array}$ 
$\begin{array}{ccccc}\mathrm{Y} & \mathrm{K} & & \mathrm{Y} & \mathrm{k} \\ \mathrm{k} & \mathrm{Y} & \mathrm{Y} & \text { World Journal of Environmental Research } & 6^{\mathrm{YI}}\end{array}$

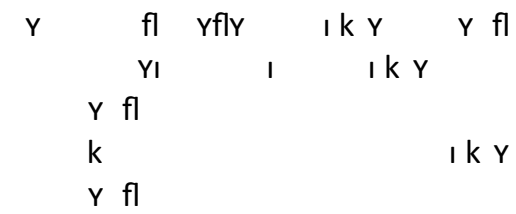

Y
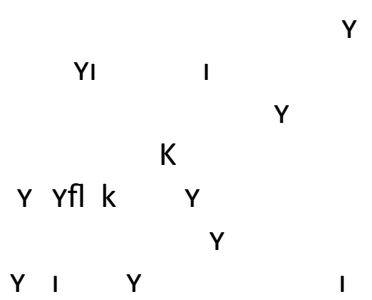

k

Y

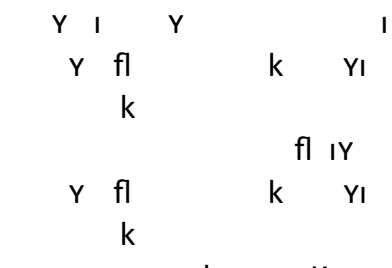

$\begin{array}{lll}Y & k & Y\end{array}$

Y Yfl k

$$
\begin{aligned}
& \begin{array}{cr}
\text { Y } & \text { I } \\
k & \text { YI K }
\end{array} \\
& \text { Y Yfl k } \\
& \text { Y I } \quad Y \\
& k \text { YIK } \\
& Y \text { Yfl k } \\
& \begin{array}{llllll}
Y & \mathrm{fl} & \mathrm{Y} & \mathrm{Y} & \mathrm{K}
\end{array}
\end{aligned}
$$$$
\text { k }
$$$$
k \quad \text { YIK }
$$$$
\text { Y Yfl k }
$$$$
\text { fl IY }
$$$$
\text { Y Yfl }
$$$$
\text { k YI K }
$$

Y

$$
\begin{array}{cccccc} 
& & & & & \\
& & k & & & \\
& & & & \\
& & & & \\
& & k & & & \\
& & & & &
\end{array}
$$$$
\text { k }
$$

k

$$
\text { k YI }
$$$$
\text { fl IY }
$$

Y

$$
\text { k YI }
$$

$$
\begin{aligned}
& k \quad \text { YIF k Y } \\
& \text { k YIF } \quad k Y \quad Y \\
& \begin{array}{lllll}
Y & \text { I } & Y & & \text { I } \\
& & k & \text { YIF } & k \text { Y }
\end{array} \\
& \text { k } \\
& \begin{array}{llr}
\text { k } & \text { Y IF } & \text { k Y } \\
& & \text { fl IY } \\
\text { k } & \text { Y IF } & \text { k Y }
\end{array}
\end{aligned}
$$
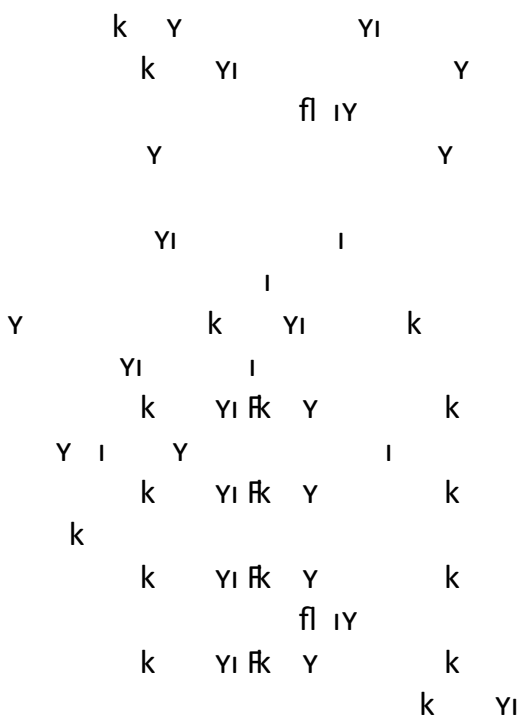

F $\mathrm{k} \mathrm{Y}$
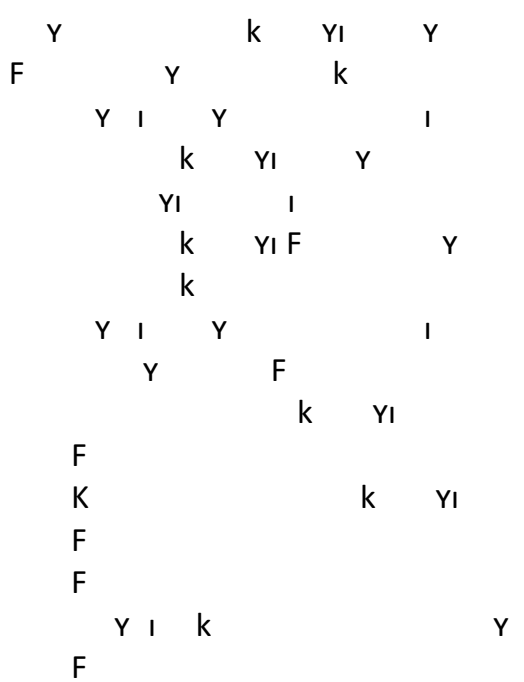

k YIF fl IY 
$\begin{array}{ccccc}\mathrm{Y} & \mathrm{K} & & \mathrm{Y} & \mathrm{k} \\ \mathrm{k} & \mathrm{Y} & \mathrm{Y} & \text { World Journal of Environmental Research } & 6^{\mathrm{YI}}\end{array}$

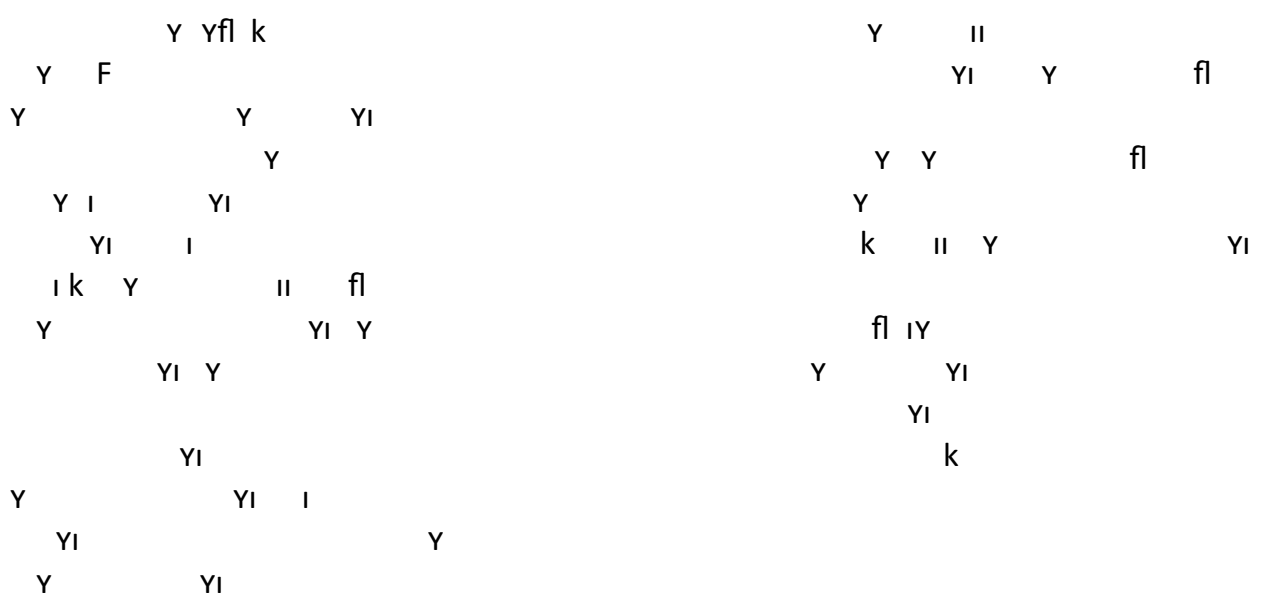

3.3 Duties of North Cyprus Assembly of the Republic Environment Committee

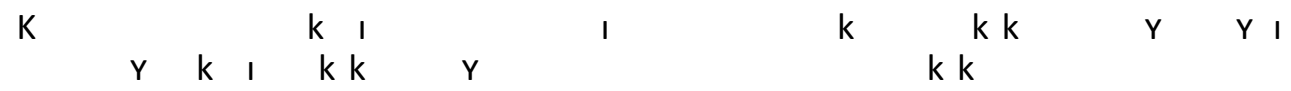

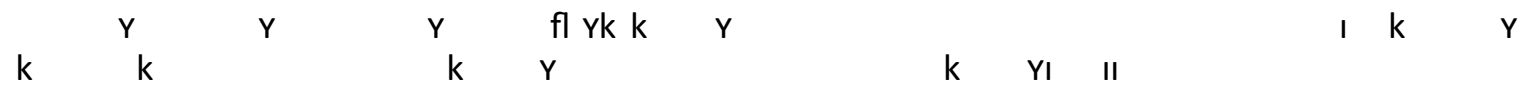

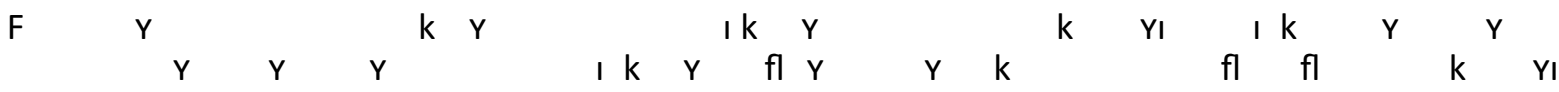

$$
\begin{aligned}
& \begin{array}{lrllllllllllllll}
k & Y I & k & Y & Y & k & l k & Y & \text { fly } & k & Y & k
\end{array} \\
& \begin{array}{lllllllllll}
k & Y & Y & k & Y & k & Y I Y & Y & \text { I }
\end{array}
\end{aligned}
$$

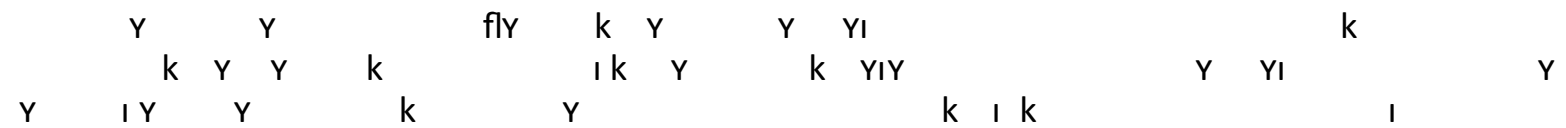

$$
\begin{aligned}
& \begin{array}{llll}
Y & \text { YI } & Y & Y
\end{array}
\end{aligned}
$$

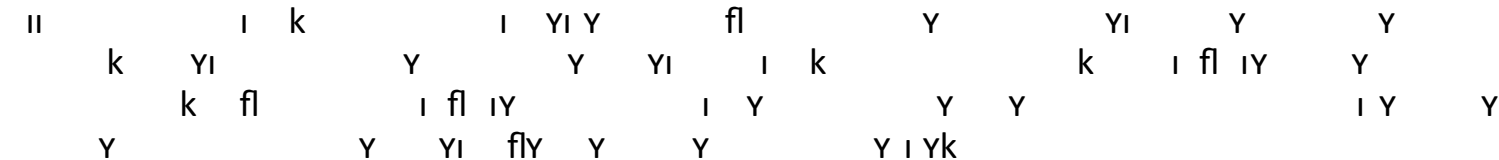

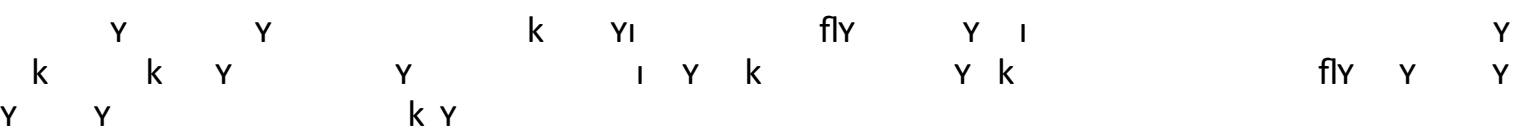

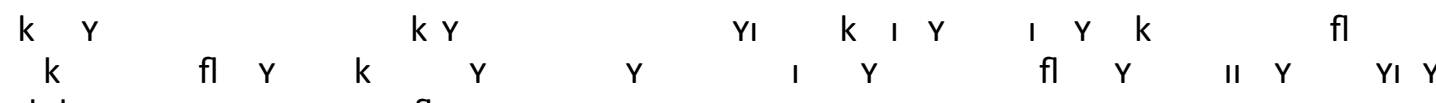

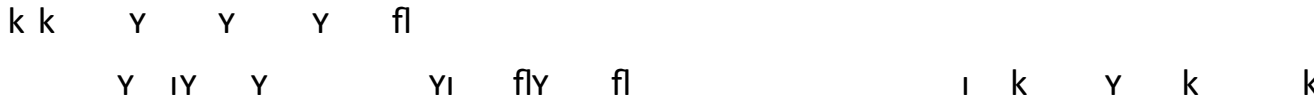

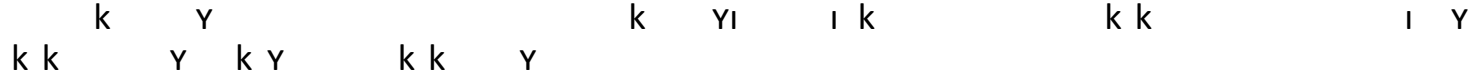

\subsection{Environmental Civil Society Organisations}

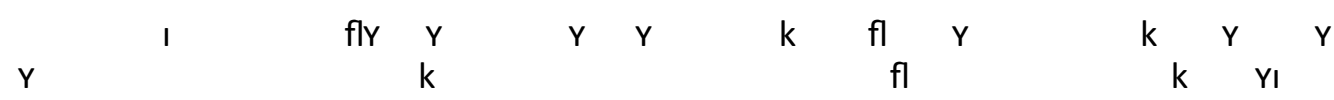


$\begin{array}{llll}\text { Y } & \text { K } & \text { Y } & \text { k }\end{array}$

World Journal of Environmental Research 6

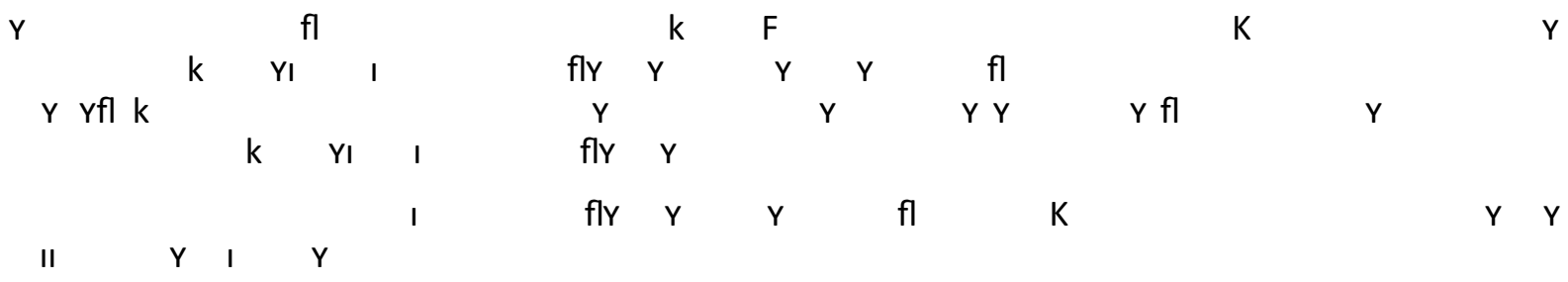

Turkish Cypriot Civil Society Organisations:

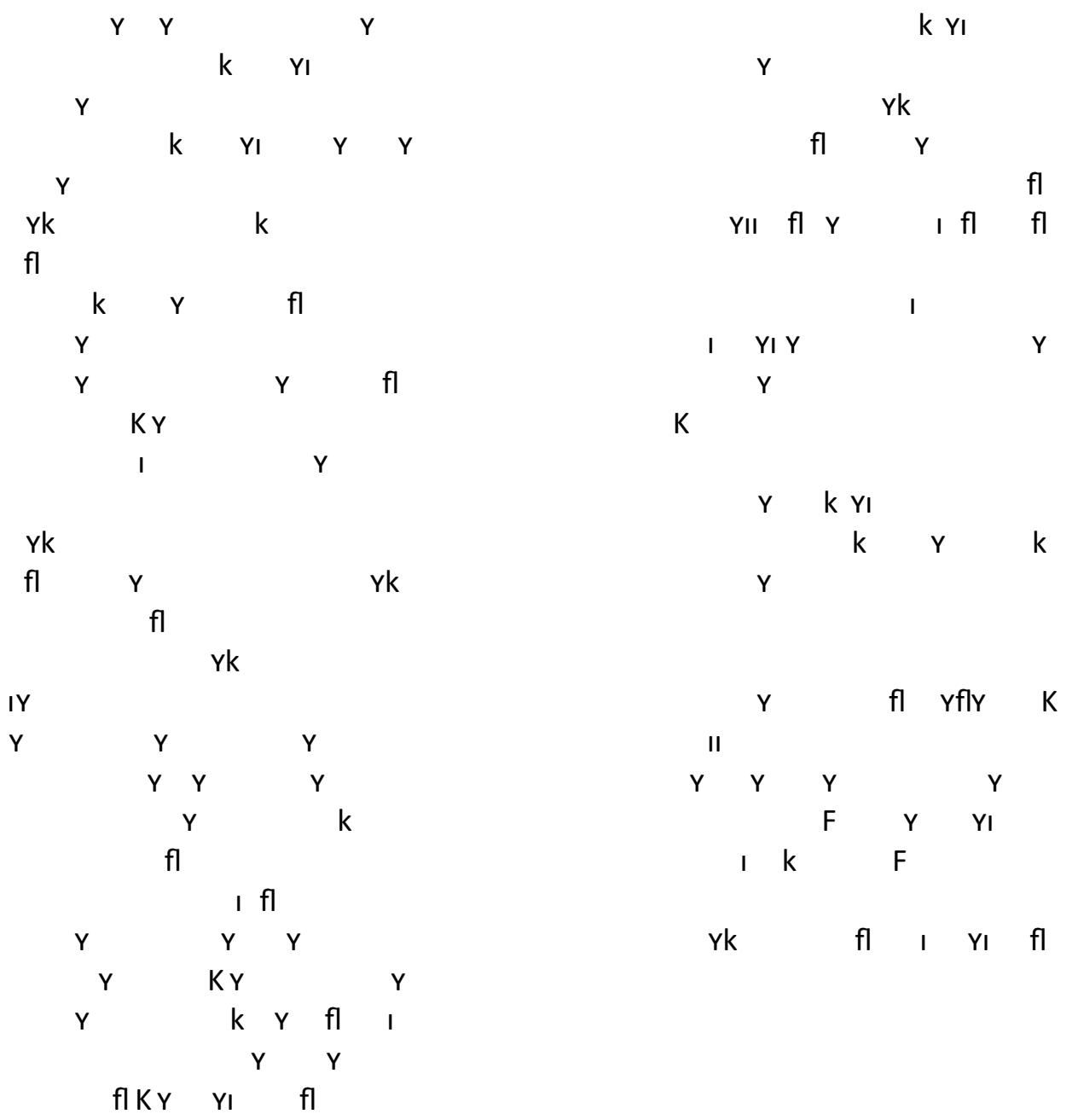

$\begin{array}{llllllll}K & \text { fly } & Y & Y & \text { fl } & \text { I } & \text { fly } & Y\end{array}$

Turkish Cypriot Civil Society Organisations:

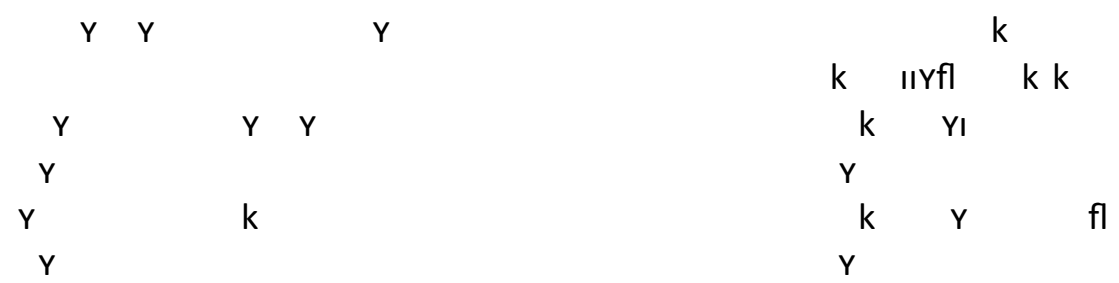




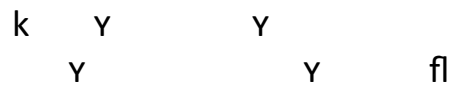

$\begin{array}{llll}k & Y & Y\end{array}$

fly i IY IIYfl a

$\begin{array}{lllll}Y & H & k & Y\end{array}$

$Y \quad Y \quad Y$

$\begin{array}{lll}Y & k & Y\end{array}$

KY

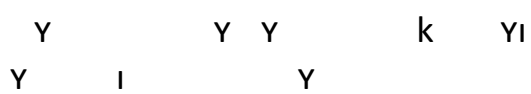

Y

Y I

$Y$

fl

Hk k fl Y

Y

Y

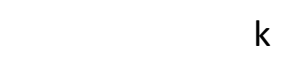

Y

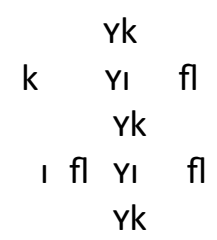

fl

Yk

IY

$\mathrm{Y}^{\mathrm{I}}$

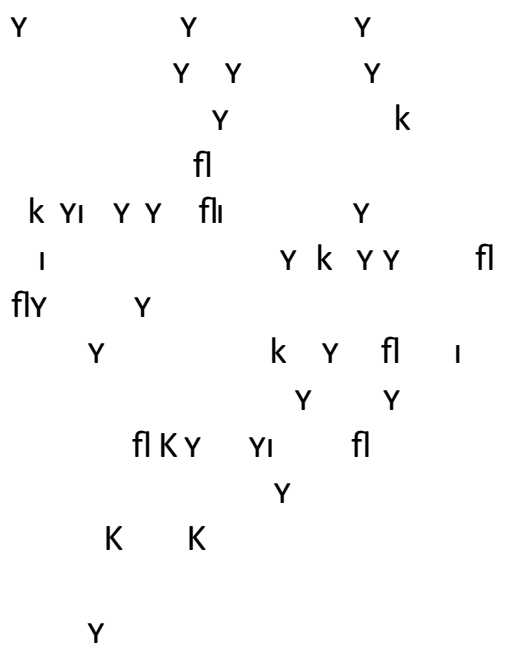

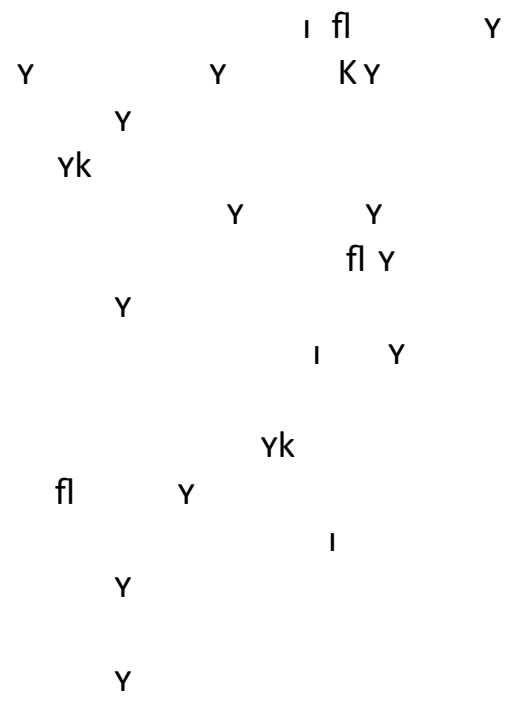

$\mathrm{F}$

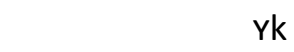

k k

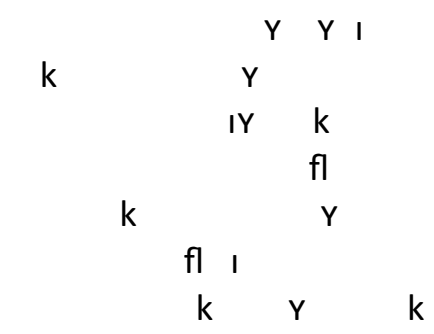

Yk Yfl $Y$ I $\quad Y$

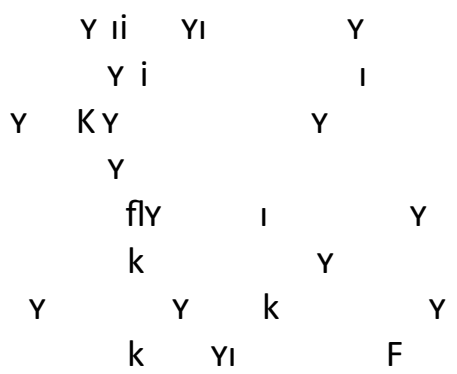

\subsection{Randomly Selected Court Decision Regarding the Environment}

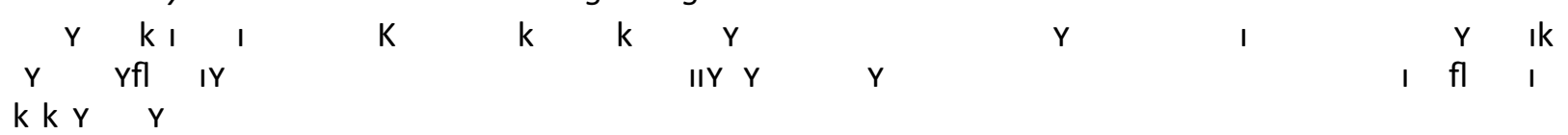

\section{Supreme Administrative Court}

On the $152^{\text {nd }}$ Article of Constitution. 
Panel of Judges: Narin F. Sefik, Mehmet Turker, Tanju Oncul.

Between

Plaintiffs:

1. Sabri Abit Muhsinoglu, Bellapais Gardens Hotel - Restaurant, Sehit Fuat Niyazi Sokak No: 3 Beylerbeyi, Kyrenia

2. Yas Tours Ltd. Bellapais, Kyrenia

- and -

Defendants:

1. Deputy Prime Ministry's Office, Ministry of Economy, Tourism, Culture and Sports, Nicosia

2. Kyrenia Municipality, Mayor, Vice Mayor, Councillors and Kyrenia Town Citizens, Kyrenia

3. Ministry of Environment and Natural Resources, Nicosia

4. TRNC Ministry of Interior, Nicosia

5. Chief Prosecutors Office representing TRNC, Nicosia.

On behalf of Plaintiffs: Att. Boysan Boyra

On behalf of Defendants No.1, 3, 4 and 5: Senior Prosecutor ilter Koyuncuoglu

On behalf of Defendant No.2: Att. Sila Miroglu

On behalf of relevant person: Att. Selcuk Gurkan and Att. Akan Gurkan.

\section{$D E C I S I O N$}

Narin F. Sefik: The plaintiffs claim that, within the framework of the project "Resolution to Waste Water Problem of Kybele Restaurant and Bellapais Monastery", all decisions given related with the project launched by the Defendant No.1 and/or building permit issued by the Defendant No.2 as a result of such decisions and/or approval are null and void and/or have no effect; the decisions and/or actions of the Defendant No.3, who did not intervene in the non-requirement of a EIA report for the related project, and did not inform the public through the issuance of a report, are null and void, and have no effect, and/or there is a negligence that should not be performed in the way of decision and/or action and/or negligence; the decision and/or actions of Defendant No.4 and/or Kyrenia District Office under Defendant No.4, who had not informed the people to be affected by this project at the permit and/or licence phase, and/or informed the public and/or related people and/or had their opinion and/or allowed the continuation of procedures are null and void, and have no effect, and/or there is a negligence that should not be performed in the way of decision and/or action and/or negligence.

The plaintiffs had based on their case on Planning Law No. 55/1989, Antiquities Law No. 60/1994, Environment Law No.18/2012 and Good Governance Law No. 27/2013.

Conclusion; The defendants were in compliance with the Antiquities, Environment and Planning Laws, however, they did not act in accordance with the Good Governance Law, they are considered as at fault by giving a permit/approval for a package treatment plant on the parcel of Bellapais Monastery owned by the Antiquities Department for the purposes of relevant person as the performance of administrative action, and considered as violating the Good Governance Law. This violation disables the stand-alone decision.

As a result, the plaintiffs are successful in their case, and the decision is taken that since there was no public participation meeting open for all public residing in the surrounding area at the phase of issuing the permit by the Antiquities Department dated 22.8.2014 by the Defendant No.2 on the sewage plant project on the Bellapais Monastery area as an issue on the environment and planning under the Good Governance Law No. 27/2013 Article 11 (2), this permit is null and/or void and shall have no effect.

The lawsuit expenses shall be decided in the favour of plaintiffs.

Narin F. Sefik Mehmet Turker Tanju Oncul 
Judge Judge Judge

14 April 2015

\subsection{Scientific Meetings on Environmental Issues}

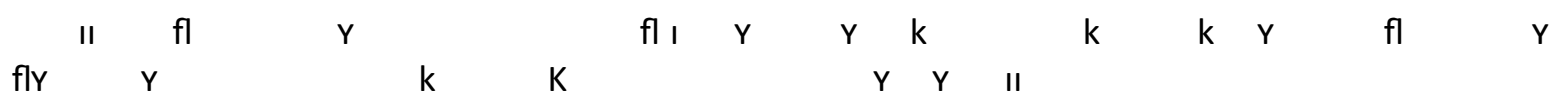

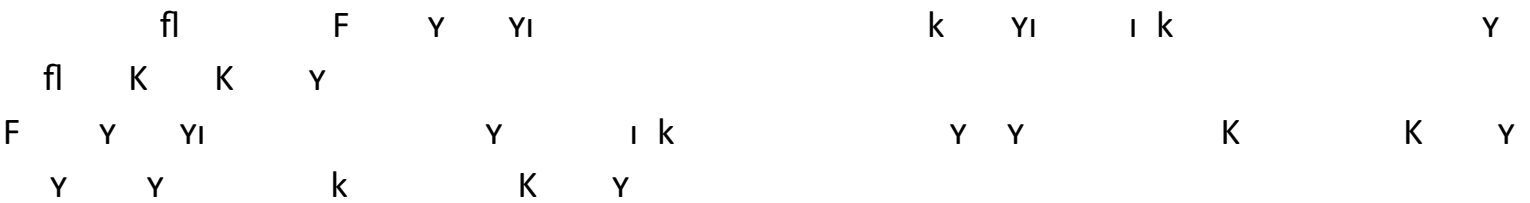

$$
\begin{aligned}
& \begin{array}{llllll}
Y & \mathrm{~K} & \mathrm{~K} & \mathrm{Y}
\end{array} \\
& \text { fl } \quad F \quad Y \quad Y I \\
& \text { K YI }
\end{aligned}
$$

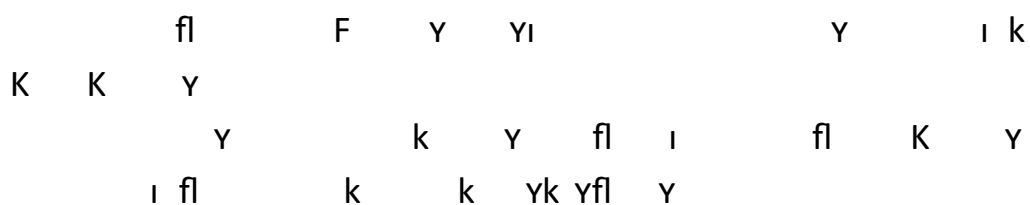

\section{Discussion and Conclusion}

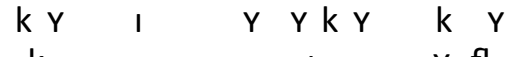

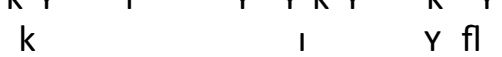

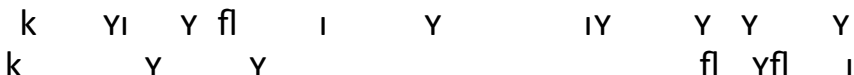

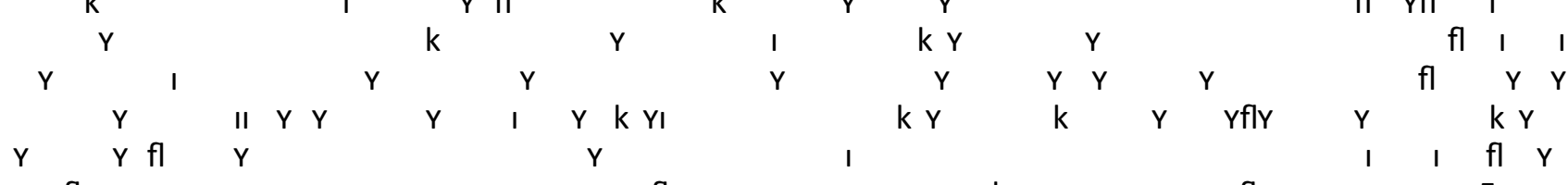

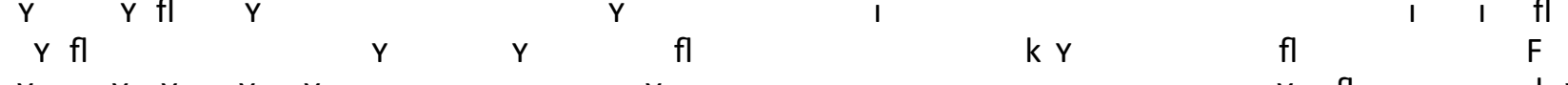

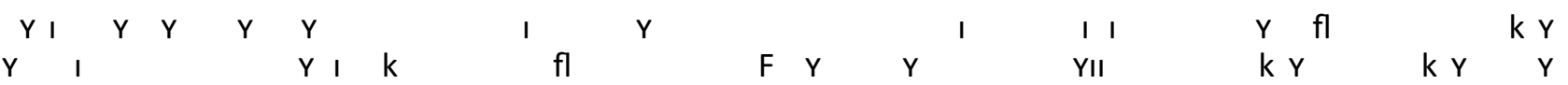

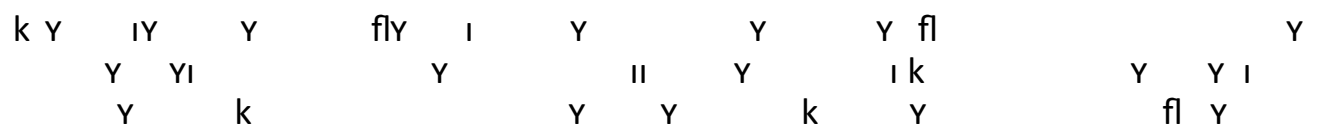

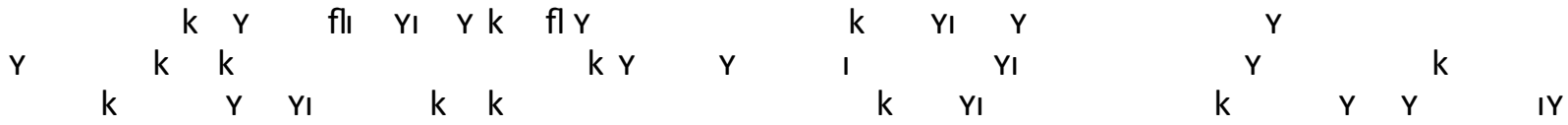

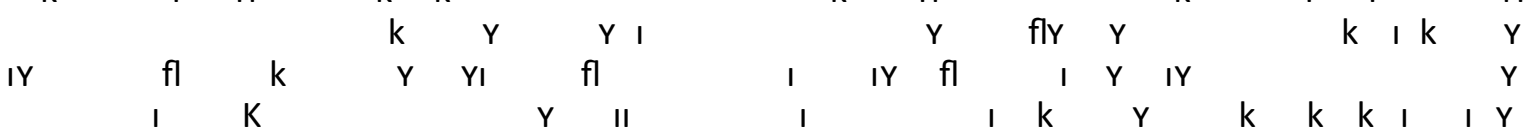

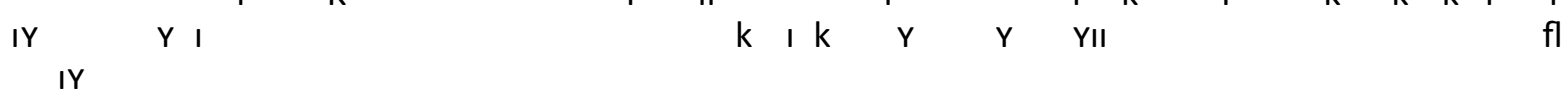

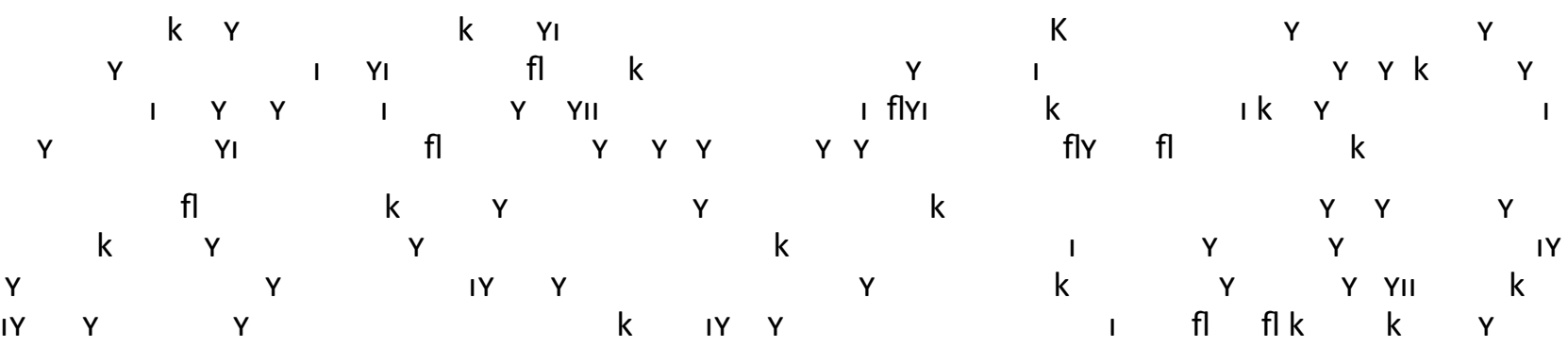


$\begin{array}{llll}Y & \mathrm{~K} & \mathrm{Y}\end{array}$

of Environmental Research 6

Y $\quad Y$
YI I

k

$\begin{array}{llll}k & Y & Y\end{array}$

World Journa

k $\quad \mathrm{Y} \quad \mathrm{Y}$

k F Y

IY

I Y

I 


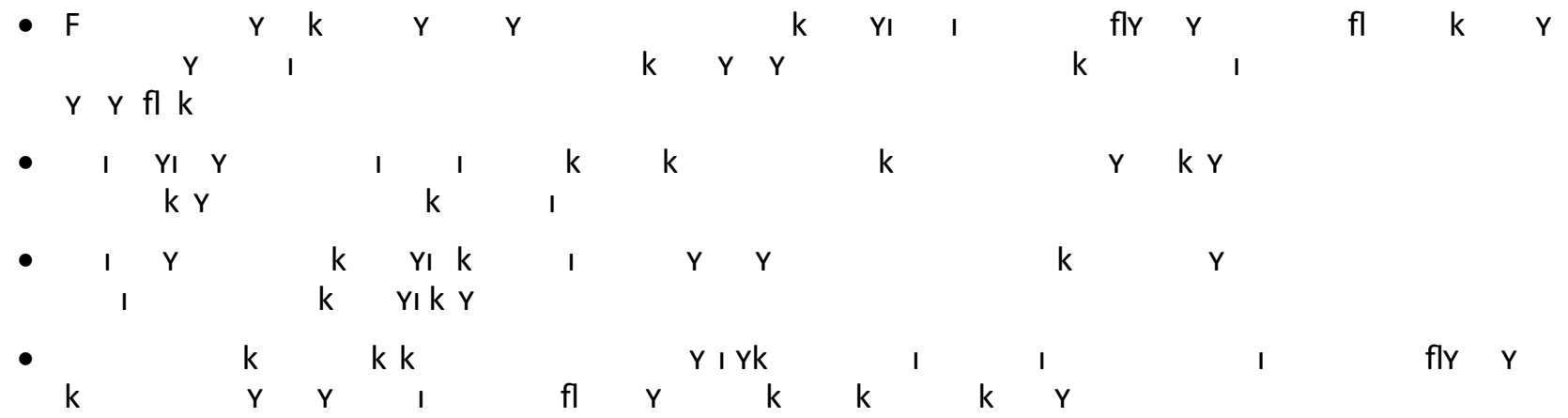

\section{References}

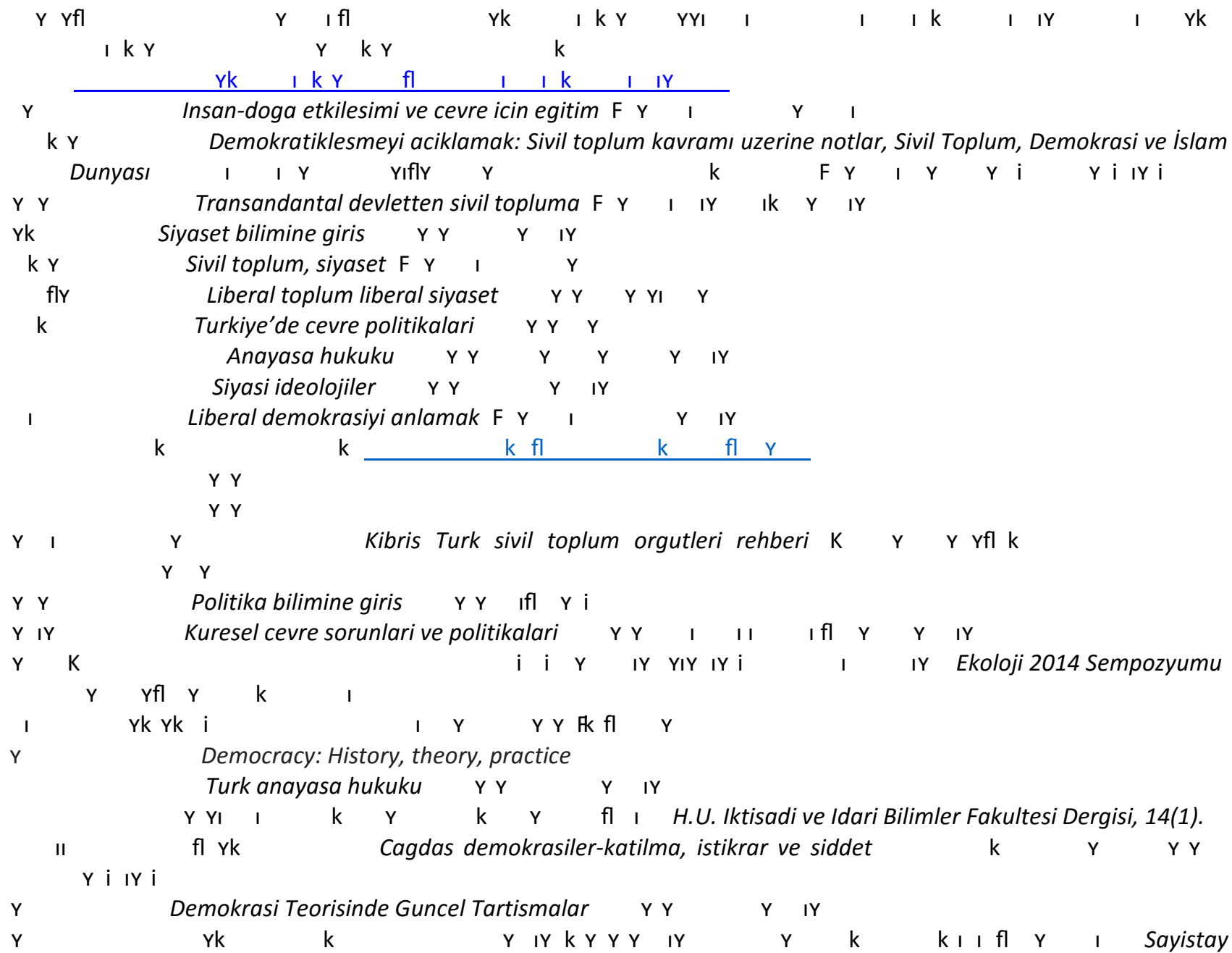

Stk"ların nasil gorunmek istediklerine karar vermeleri, onlarin toplumsal kimligi acisindan yasamsal $\begin{array}{lllllllllllllllll}\text { oneme sahiptir } & \mathrm{I} & \mathrm{k} & \mathrm{Y} & \mathrm{Yk} & \mathrm{Y} & \mathrm{k} & \mathrm{Y} I \mathrm{Y} & \mathrm{F} & \mathrm{Y} & \mathrm{I} & \mathrm{Y} & \mathrm{Y} & \mathrm{I}\end{array}$ 